\title{
Plugin of Recommendation Based on a Hybrid Method for the Ranking of Documents in the E-Learning Platforms
}

\author{
Hicham Moutachaouik ${ }^{1}$, Hassan Douzi ${ }^{1}$, \\ Abdelaziz Marzak ${ }^{2}$, Hicham Behja ${ }^{3}$, and Brahim Ouhbi ${ }^{3}$ \\ ${ }^{1}$ Laboratory IRF-SIC, Faculty of Sciences Agadir, \\ University Ibn Zohr, \\ BP.8106 Hay Dakhla, Agadir, Morocco \\ gotohichamegmail.com, \\ douzi_h@yahoo.fr \\ ${ }^{2}$ Laboratory of Information Technologies and Modeling, \\ Faculty of Science Ben M'sik Casablanca, \\ BP.7955 Casablanca, Morocco \\ marzak@hotmail.com \\ ${ }^{3}$ Laboratory Command and Control of Production System, \\ ENSAM-Meknes, \\ BP.4024 Beni M'hamad, Meknes, Morocco \\ h_behja@yahoo.com, \\ ouhbib@yahoo.co.uk
}

\begin{abstract}
The objective of this work is the conception and the realization of a recommendatory system, using concepts of the web usage mining and being inspired by approaches to information filtering. This system includes a new hybrid method to rank documents web, in order to propose to the Webmaster (or admin) of platform e- learning the best available documents based of the historical to research done by learners.

It is, actually a meta-search engine on the web, integrated into the e-learning platform to keep surfing traces of the learner during his searching. This will permit to have a usage basis that will be used by the system to help webmaster (admin) to make decisions about the documents to be added to the platform. The elaborated system will make it passible to propose help and assistance to learners of the platform.
\end{abstract}

Keywords: e-learning, web usage mining, information filtering, ranking, recommendation system, Moodle, classification.

\section{Introduction}

Due to the exponential increase in the amount of resources available and accessible on the web, Recommendation systems have seen their popularity grow in recent years. Combining techniques of information filtering, personalization, artificial intelligence, 
social networks and human-computer interaction, recommendation systems provide users with suggestions to meet their informational needs and preferences. Indeed, recommendation systems are particularly in demand in e-commerce applications. For example, the Amazon site recommends all kinds of products (movies, music, books, etc...) $[1,2]$.

To Produce recommendations, a number of approaches is possible: (i) the approach by content [3] which makes recommendations by comparing the semantic content of resources with the user's tastes, (ii) the approach based on knowledge [4] that makes recommendations by exploiting knowledge about the user and pre-established heuristics, and (iii) the approach by collaborative filtering [5], which makes recommendations by analyzing, at the same time, the user's opinions and those of other users about the resources they have consulted.

All these approaches require a ranking of documents before presented to the user system. For example, in the latest approach that we interests the most (collaborative filtering), documents is presented in order of decreasing evaluation, the latter is usually given as a vote.

This paper, proposes a Plugin what can integrate on any platform e-Learning (in our case, we used the platform open source moodle) to keep tracks of the web searches made by learners (student), in order to use it for the recommendation. This Plugin also includes a new hybrid method to rank documents web before presenting to the learner.

This ranking is given according to order of decreasing relevance score of documents deemed relevant. This score is calculated according three phases. First, we inspired from the collaborative filtering to calculate the score of vote for the document. Second, we use the formula chan to measure the degree of appreciation of the document by the learner. Finally, we develop a new function called $\lambda$ method to combine these two measures (score of vote, formula chan) to calculate the relevance score.

The results show the quality of recommendations by contribution to our former work $[6,7]$ mainly through the addition of other criteria that have improved the results in order to help learners in their learning while trying to overcome the major problems of recommender systems(Critical Mass, Cold Start, Principle of induction) [7].

The rest of the article is organized as follows:

In section 2, we describe the working process of the proposed solution as well as the methodologies of ranking. In Section 3, we evaluated our Plugin by analyzing the learners' behaviors of the platform e-learning moodle. We terminate by conclusions and perspectives of our work in the section 4 .

\section{Process of Operation and Methodologie for Ranking of Document}

\subsection{Process of Operation}

The system (Plugin) that was integrated in the platform e-learning to study the behavior of learners and produce recommendations is named MX-Search. 


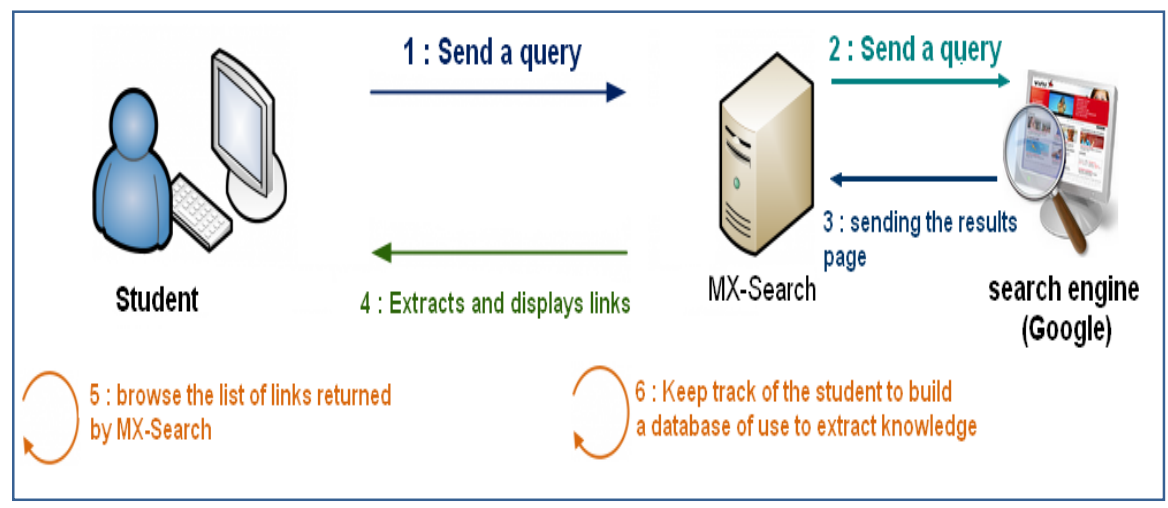

Fig. 1. Process of operation of MX-Search

MX-Search retrieves and displays the search results returned by the search engines (Google, Yahoo, Bing) while keeping track of the learner to make recommendations (figure1).

\subsection{Allocation of the Link Visited in a Category of Courses}

Before raking documents, we must classify the links returned by the search engine web. This will allow categorizing all the documents requested by all learners of the platform during their navigation.

To achieve this categorization, we utilize the method of classification using $\mathrm{K}$-means [8]. We consider the categories of courses as classes that we attribute objects (web documents visited by the learner).

To calculate the similarity between a document and a category of course, we utilize the lexical similarity [9].

Algorithm of attribution of a link to a category of courses:

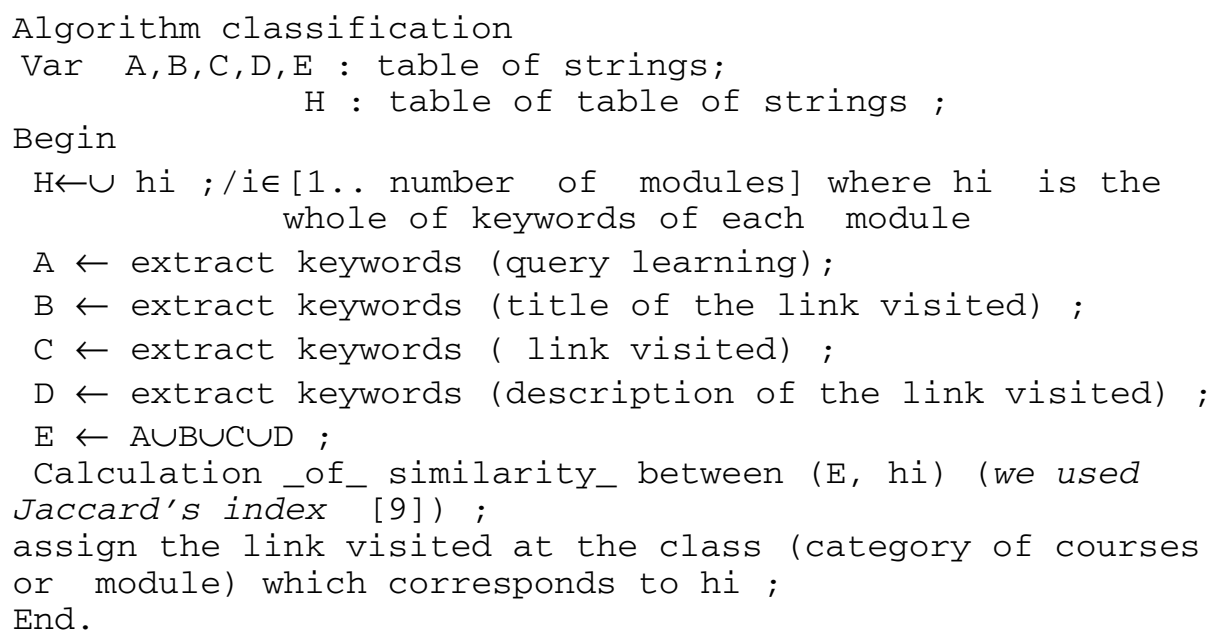




\subsection{Methodology Followed for Ranking of Documents}

\section{How to Calculate the Score of Vote?}

To get the preferences of users, the collaborative filtering approach uses either the preference relation or the utility function (eg voting). Indeed in the second case which interests, us most is proposed to the user to give his opinion on a scale of integer values and relatively reduced task (usually a value between 1 and 5 or 1 and 7) [1]. But this voting task with note is very hard for the learner. This prompted us to propose a new scale of assessment instead of the whole scale of values.

To do this, we ask the learner for example:

\section{How do you find the document? \\ Useless, Poor, Average, Good or Excellent}

The response will be closer to the real context and facilitates the assessment of the learner. Then, we assign for each assessment a note (Useless=1, Poor=2, Passable =3, Good=4, Excellent=5).

Finally, we calculate the score of vote defined by:

$$
\text { score of vote }(\text { doc })=\operatorname{sum}(\alpha i \text { vote }(i)) / \operatorname{sum}(\alpha i)
$$

With ai: weight of vote according to the level of the learner

\section{How to Calculate Formula Chan?}

Explicit evaluations require more users' effort. As a result, users often tend to avoid this burden by leaving the system permanently or providing erroneous assessments.

In contrast, the deduction of such assessments by the single observation of user behavior is much less intrusive.

A real example of inference implicit evaluations is the formula proposed by Chan (1999) [2], to predict whether a web page has been appreciated or not.

This formula is based largely on information that can be harvested from the data protocol communication. Indeed, it is calculated based on the history, the bookmark, the contents of pages and the access log.

Finally, Chan (1999) defines the degree of interest in a page:

$$
\begin{gathered}
\text { Interest }(\text { Page })=\text { Frequency }(\text { Page }) *(1+\text { IsBookmark }(\text { Page })+\text { Duration }(\text { Page })+ \\
\text { Recency }(\text { Page })+\text { LinkVisitPercent }(\text { Page }))
\end{gathered}
$$

In our system this formula was modified by adding weights to the variables in order to promote and give prominence to a variable contribution to the other. Formula Chan becomes:

$$
\begin{gathered}
\text { Interest }(\text { Page })=\text { Frequency }(\text { Page }) *\left(1+\alpha * I s \text { Bookmark }(\text { Page })+\beta^{*}\right. \\
\text { Duration } \left.(\text { Page })+\delta * \text { Recency }(\text { Page })+\gamma^{*} \text { LinkVisitPercent }(\text { Page })\right)
\end{gathered}
$$

With $\alpha, \beta, \delta, \gamma$ : the weight of the variable and $0<\alpha, \beta, \delta, \gamma<1$ and

$$
\alpha+\beta+\delta+\gamma=1
$$


By experimentation, to have a better recommendation, we offer $\alpha=\delta=\gamma=0.3$ and $\beta=0.1$.

\section{Raking Using the $\lambda$ Method?}

Our contribution in this regard is made using our method that we have developed called the $\lambda$ method, which consisting of combining the explicit criterion (score of vote) with the implicit criterion (Formula Chan) to produce recommendations.

$$
\text { score of pertinence }(\text { doc })=\lambda \text { score of vote }(\text { doc })+(1-\lambda) \text { Interest }(\text { doc })
$$

With $\lambda$ : the weight of the variable and $0<\lambda<1$

To keep the weight distribution of the variables and for given the same importance, we give 0.5 to $\lambda$ value.

\section{Exploration and Analysis of the Behavior of Students of the Platform E-Learning Moodle: LP Java/C++}

To test the functioning of our Plugin MX-Search, we integrated it in the platform elearning moodle $[10,11]$ of the license professional Java/C++ of the faculty of sciences of Casablanca, Morocco.

\subsection{Assist the Learner to Browse the Result of His Research on the Web}

The learner from the platform e-learning LP Java/C++ can carry out research on the web while remaining on the platform (figure 2, 3, 4).

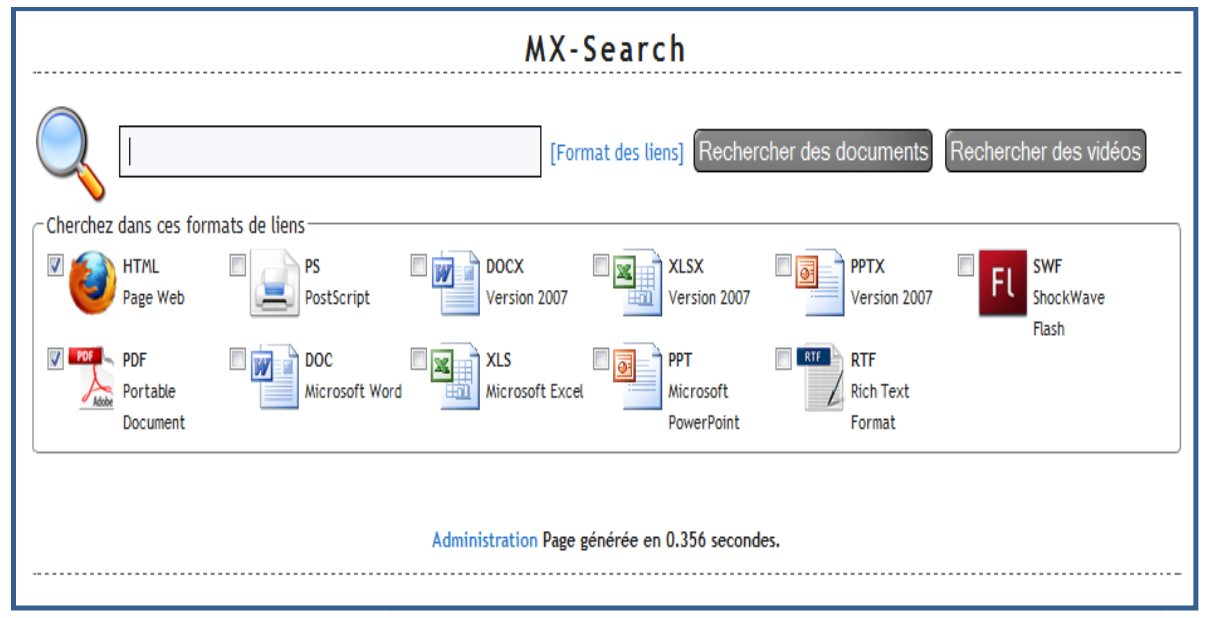

Fig. 2. Interface to conduct research on the web 


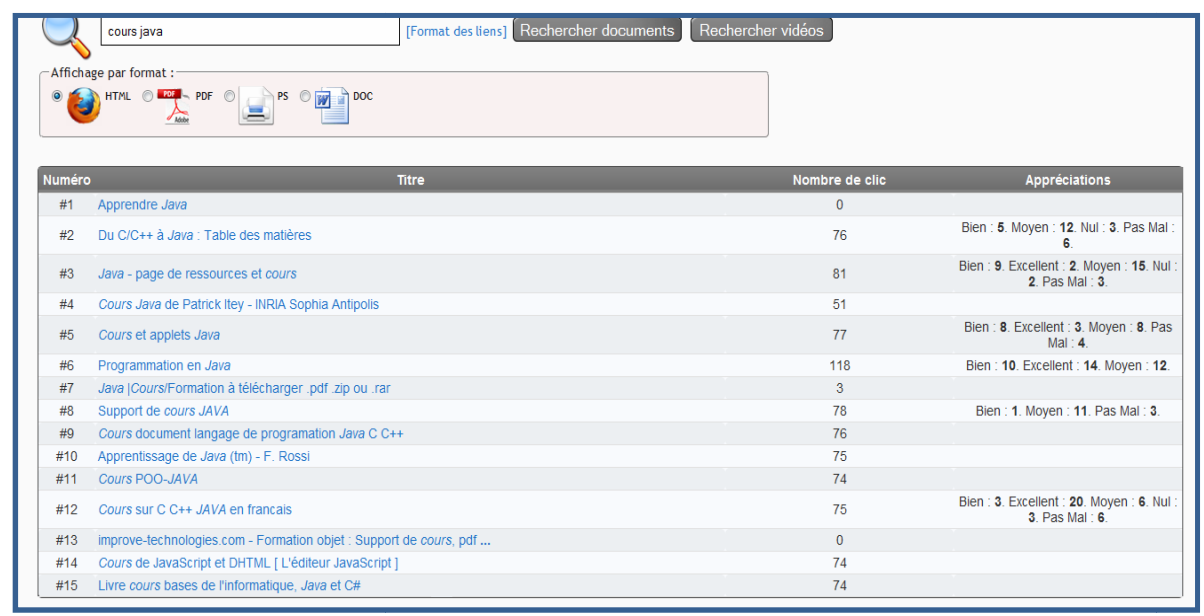

Fig. 3. Interface for the result of the search for a learner

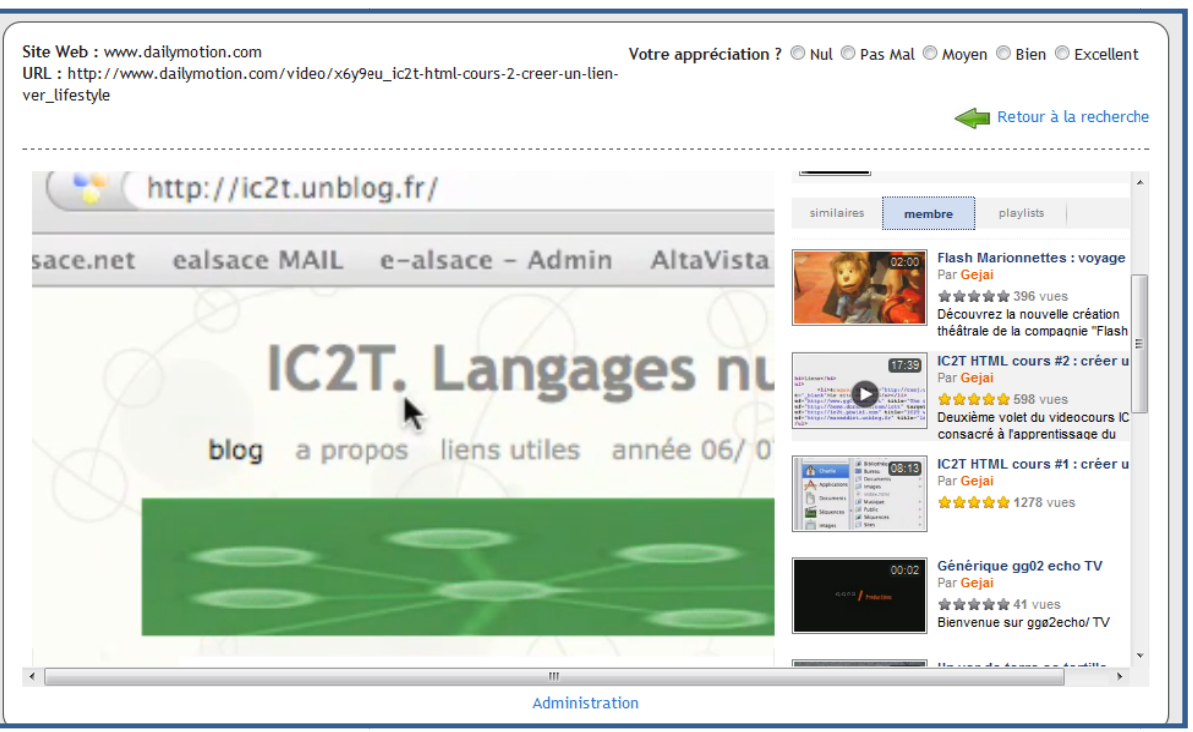

Fig. 4. Interface to view the contents of the link web and vote

\subsection{Guide the Administrator of the Platform to Extract Knowledge}

The administrator (web master or teacher) the platform e-learning moodle of the license professional Java/C ++ can choose the chain, the desired module as well as the criterion of ranking to make decisions concerning web documents to add in the platform e-learning (figure5). 
$\begin{array}{ll}\text { Choisir une filière } & \text { Divers }- \\ \text { Choisir un module } & \text { Divers }\end{array}$

Proposer moi les meilleurs documents?

Je voudrais savoir :

les meilleurs documents qui existent selon le critére : Appréciation?
les meilleurs documents qui existent selon le critére : Ratio?
les meilleurs documents qui existent en combinant les différentes critéres?
les meilleurs documents qui existent durant une période?
les meilleurs documents qui existent selon le critére : Appréciation_F.Chan?

Fig. 5. Interface to choose the criteria of knowledge extraction

After having chosen the java module for example, the system ranks the documents according to their relevance according to the point of view of the learner and I or formula chan (figure $6,7,8$,). This ranking will allow learners to have additional resources to understand the module.

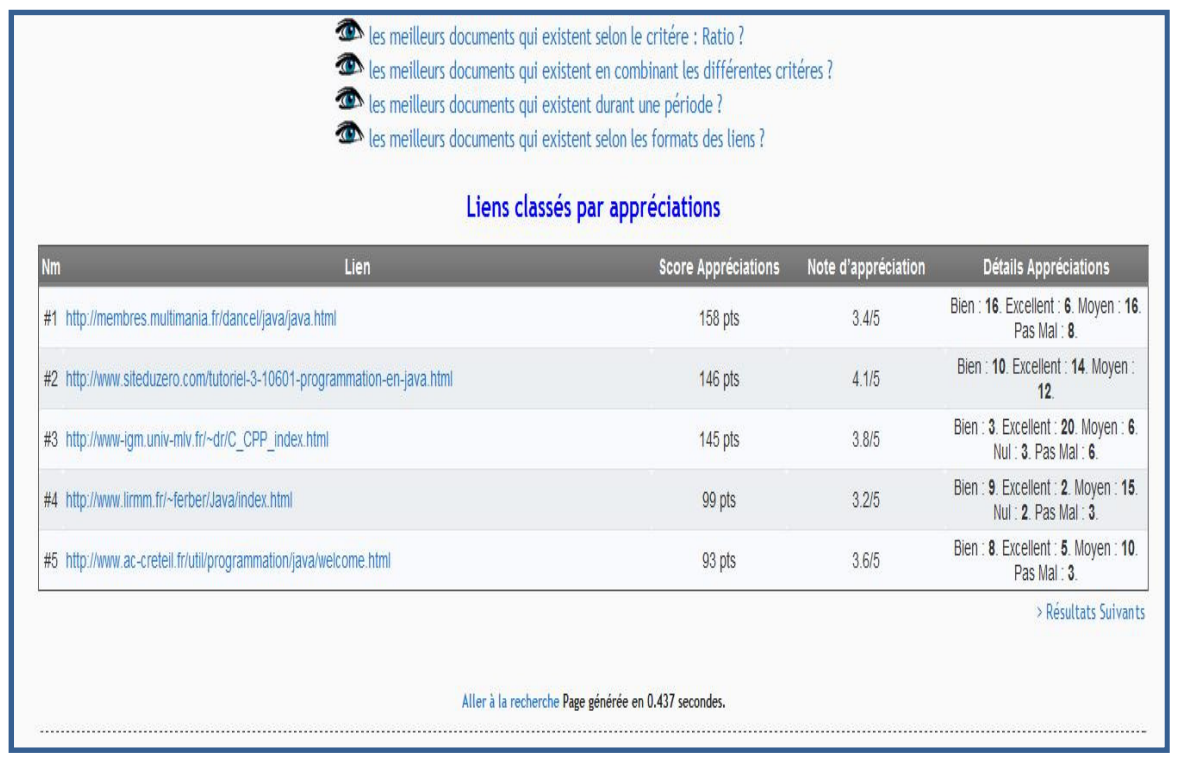

Fig. 6. Result obtained for the module java according to the criterion: Score of vote 


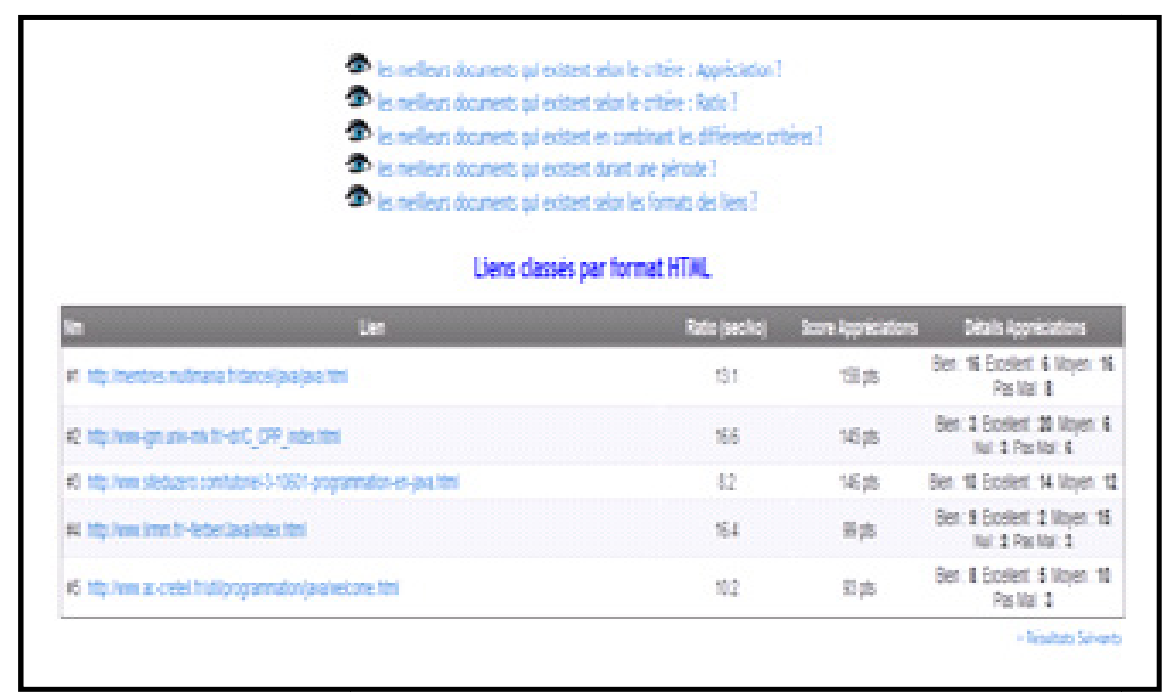

Fig. 7. Result obtained for the module java according to the combination of criteria and document type (html)

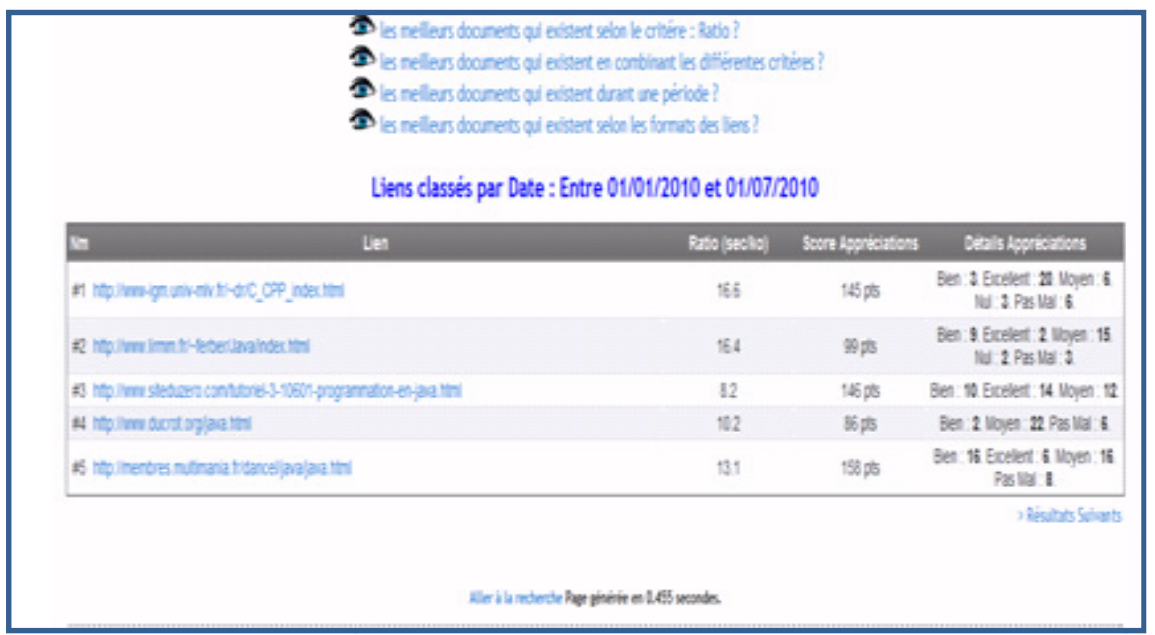

Fig. 8. Result obtained for the module java according to the combination of criteria: Score of vote, Interest (page) and period of search

\section{Conclusion and Perspective}

In this work, we have shown how the techniques of web usage mining and the ranking method can contribute to produce recommendations for improving the services offered by the platforms e-learning to guide and facilitate learning of learners. 
The solution suggested MX-Search is based on a system of search of information web, on the concepts of web usage mining, on novel method hybrid of ranking of documents, K-means, and the filtering of information to keep track about navigation learners during their research in the web while involving then: (vote, click ...).

This will have a basis of use that will be used by the system to assist the administrator (Webmaster or teacher) to take decisions on the best documents existing on the web so to add them as additional resources in the platform, so that these learners or other promotions can benefit of them.

The hybrid method of ranking that we propose also increases the quality of recommendations in relation to use only techniques of the collaborative filtering.

This work is still being improved, as regards the topics and the features.

\section{References}

1. Brun, A., Hamad, A., Buffet, O., Boyer, A.: Vers l'utilisation de relations de préférence pour le filtrage collaboratif, Actes du dix-septième congrés francophone AFRIF-AFIA sur la Reconnaissance des Formes et l'Intelligence Artificielle (RFIA 2010), Caen, France (2010)

2. Zaier, Z.: These Modèle multi-agents pour le filtrage collaboratif de l'information (Janvier 2010)

3. Pazzani, M.J., Billsus, D.: Content-Based Recommendation Systems. In: Brusilovsky, P., Kobsa, A., Nejdl, W. (eds.) Adaptive Web 2007. LNCS, vol. 4321, pp. 325-341. Springer, Heidelberg (2007)

4. Burke, R., Hammond, K., Cooper, E.: Knowledge based navigation of complex information spaces. In: Proc. of the 13th National Conference on Artificial Intelligence (AAAI 1996), Menlo Park, Canada, pp. 462-468 (1996)

5. Goldberg, D., Nichols, D., Oki, B.M., Terry, D.: Using collaborative filtering to weave an information tapestry. Communications of the ACM 35(12), 61-70 (1992)

6. Moutachaouik, H., Marzak, A., Behja, H., Douzi, H., Ouhbi, B.: Système de Recommandation pour améliorer le service de recherche d'information dans les plates formes Elearning: Application sur la plate forme E-learning Moodle. In: Proc. of the the Second Edition of the International Conference on Next Generation Networks and Services (NGNS 2010), Marrakesh, Morocco, July 8-10 (2010)

7. Moutachaouik, H., Marzak, A., Behja, H., Douzi, H., Ouhbi, B.: Recommendation system to improve service to search for information in e-learning platforms: Application on Elearning platform Moodle. In: Proc. of the 2nd International Conference on Multimedia Computing and Systems (ICMCS 2011), Ouarzazate, Morocco, April 7-9 (2011)

8. Hartigan, J.A.: Clustering Algorithms. John Wiley \& Sons (1975)

9. Sahami, M., Heilman, T.: A web-based kernel function for measuring the similarity of short text snippets. In: Proceedings of WWW 2006, pp. 377-386 (2006)

10. Al-Ajlan, A., Zedan, H.: Why Moodle. In: 2008 12th IEEE International Workshop on Future Trends of Distributed Computing Systems, FTDCS, pp. 58-64 (2008)

11. Dougiamas, M.: Moodle (2008), http: / /www. Moodle.org 